\title{
Correlation of Clinical Findings of Infantile Hypertrophic Pyloric Stenosis with Ultrasonography and Operative Findings
}

Karim $\mathrm{MR}^{1^{*}}$, Khan $\mathrm{H}^{2}$

${ }^{1}$ Dr. Md. Rezaul Karim, Associate Professor, Department of Pediatric Surgery, Enam Medical College Hospital, Dhaka, Bangladesh ${ }^{2}$ Dr. Humaira Khan Sonologist, Anwar Khan Modern Medical College Hospital, Dhaka, Bangladesh

DOI: $10.36347 /$ sjams.2020.v08i12.031

| Received: 23.11.2020 | Accepted: 05.12.2020 | Published: 29.12.2020

*Corresponding author: Dr. Md. Rezaul Karim

Abstract

Original Research Article

Introduction: Infantile hypertrophic pyloric stenosis (IHPS) is characterized by hypertrophy of the pyloric muscularis propria, predominantly involving the circular layer and subsequent narrowing of the pyloric outlet. Aim of the Study: To find out the correlation of clinical findings and ultrasonography findings in diagnosis of infantile hypertrophic pyloric stenosis. Material \& Methods: This prospective comparative study was conducted in Dhaka Shishu (Children) Hospital, Dhaka, Bangladesh during the period from February 1997 to October 1998 in a period of 21 months. The data were collected for all 31 patients. Following, collection of all the required data, these were checked, and tabulated into the computer using the SPSS/PC software 23. Results: During my study period February 1997 to October 1998 total surgical admission was 4006 and infantile hypertrophic pyloric stenosis patients (IHPS) were 31 . So IHPS represented $.77 \%$ of the total surgical admission during the study period in DSH. Correlation of clinical and ultrasonogram findings with operative finding, clinical findings true +ve 20(64.52\%), true -ve 2(6.45\%), false +ve 1(3.23), false -ve 8(25.81) and ultra-sonogram observation true +ve 27(87.10\%), true -ve 2(6.45\%), false +ve 2(6.45\%), false -ve 2(6.45\%)and then finally operation needed IHPS $29(93.35 \%)$ also others than IHPS 2(6.45\%). Correlation of pattern of sensitivity and specificity in clinical findings $93.1 \%$ and 50\%, ultra-sonogram findings $71.43 \%$ and $66.67 \%$. Conclusion: In conclusion we would like to advice that infantile hypertrophic pyloric stenosis is a most common cause of non-bilious vomiting in an infant. Its diagnosis not so difficult in most cases. The diagnosis being made primarily by palpation of the hypertrophied pylorus.

Keywords: Clinical findings, Infantile, Hypertrophic Pyloric Stenosis, Ultrasonography.

Copyright $\odot 2020$ The Author(s): This is an open-access article distributed under the terms of the Creative Commons Attribution 4.0 International License (CC BY-NC 4.0) which permits unrestricted use, distribution, and reproduction in any medium for non-commercial use provided the original author and source are credited.

\section{INTRODUCTION}

In 1627, Hildanus first described pyloric stenosis. More characteristic clinical and postmortem findings of IHPS were reported by Patrick Blair in 1717. Hirsch sprung a Danish Pediatric Surgeon, described clinical findings of the disease and established the pyloric stenosis in 1888 at a major pediatric congress and awareness of the condition was aroused in the medical world. Infantile hypertrophic pyloric stenosis (IHPS) is characterized by hypertrophy of the pyloric muscularis propria, predominantly involving the circular layer and subsequent narrowing of the pyloric outlet [1]. Infantile hypertrophic pyloric stenosis is one of the most common abnormalities occurring in the first few month of life, responsible for non-bilious vomiting [2]. There is marked hypertrophy of the circular muscles in pylorus. The pyloric canal is lengthened and the whole pylorus becomes olive shaped and firm Dudeon, 1993. In early years surgical treatment of pyloric stenosis carried an unacceptably high mortality rate $[2,3]$. But with the development of operative technique and early diagnosis [4], barium meal study and more commonly used noninvasive U. S. technique, advances in fluid therapy and anaesthesia [5], improved treatment of metabolic alkalosis, and appropriate treatment before developing serious complication. So today mortality rate has come down to about $0.4 \%$ or less [8]. Immediate and permanent relief of symptoms is obtained by a simple operation pyloromyotomy. Incidence of infantile hypertrophic pyloric stenosis is about 3 per thousand live births [9]. It is most common in whites, less common in black; and rare in oriental individuals. Boys are more often affected with an average male female ratio 4:1 [10]. The disorder often occurs in first born male child, and there is a strong familial pattern of inheritance [11]. The expression of pyloric stenosis is dependent upon the genetic influence [12]. Now a days diagnosis of IHPS in not difficult. In most cases it is possible to diagnose by clinical findings alone. The diagnosis of IHPS being made primarily by palpation of the hypertrophied pylorus. Where clinical confirmation is in doubt, 
ultrasonography accurately diagnose the case of IHPS. Telle and Smith first described the use of ultrasonography to diagnosis of IHPS in 1977. In difficult clinical situations, sonographic examination for pyloric stenosis is simple repeatable, and avoids the risk of radiation therapy to barium meal examination. Pyloromyotomy can be performed by open laparotomy or by laparoscopy with permanent relief of symptoms.

\section{OBJECTIVES}

\section{a) General Objective}

- To find out the correlation of clinical findings and ultrasonography findings in diagnosis of infantile hypertrophic pyloric stenosis.

\section{b) Specific Objectives}

- To gather knowledge regarding incidence, socioeconomic status, clinical presentation and management of infantile hypertrophic pyloric stenosis in Bangladeshi population.

\section{Methodology And Materials}

This prospective comparative study was conducted in in Dhaka Shishu (Children) Hospital, Dhaka, Bangladesh during the period from conducted from February 1997 to October 1998 in a period of 21 months. In each case, information about the patient were obtained in the form of a questionnaire (Appendix-I) after obtaining the consent of the parent or guardian on a consent form (Appendix-II). Detailed history was taken from the patient's mother or attendant. The questionnaire included age, sex, family history, weight, socio-economic status, address of the patient, antenatal and post-natal period, presenting complaints, previous treatment and detailed physical examination. A detailed history of onset of vomiting at age, whether the vomiting was projectile or nonprojectile, whether it was whitish, bilious or nonbilious, whether it was blood mixed of coffee ground in color. Duration between feeding and onset of vomiting, demanding for food following vomiting, whether there was any visible peristalsis or mass in the upper abdomen. Was there any sign of dehydration and failure to thrive? All these were noted. The associated signs were also recorded. Information were sought regarding diagnosis and treatment. The information obtained through the above process was followed up and supplemented by records of physical findings, laboratory, radiology and imaging study, the treatment administered and the correlation of clinical diagnosis and ultrasonography diagnosis was reviewed finally by operative diagnosis and the outcome of the treatment. The data were collected for all 31 patients. Following, collection of all the required data, these were checked, and tabulated into the computer using the SPSS/PC software 23 .

\section{Inclusion Criteria}

All patients suffering from the symptoms of infantile hypertrophic pyloric stenosis, were admitted in the surgery department of DSH from February 1997 to October 1998 and undergone investigations and operative treatment.

\section{Exclusion Criteria}

Patients with symptoms of infantile hypertrophicd pyloric stenosis but operation were not done. Patients with nonbilious vomiting and over 1 year age.

\section{RESULTS}

During my study period February 1997 to October 1998 total surgical admission was 4006 and infantile hypertrophic pyloric stenosis patients (IHPS) were 31 . So IHPS represented $.77 \%$ of the total surgical admission during the study period in DSH (Figure1).The gender distribution of the participant's male ware $27(87.10 \%)$ and female were $4(12.90 \%)$. The age of the patients in overall group ranged from 0-5 months. Highest number of patients was within 1-2 months age group was $22(70.97 \%)$ and lowest number of patients was above 2-5 months age group was 3(9.68\%) and lower number of patients 0-1 month age group was $6(19.35 \%)$. In Socio-economic condition the lower income group $9(29.03 \%)$, middle income group $19(61.29 \%)$ and higher income group 3(9.68\%). Inhabitant of the patients Rural area 19(61.29\%) and urban area $12(35.71 \%)$. Although the number of patients varied from season to season, there was little relationship between the admission in surgical unit and admission of infantile hypertrophic pyloric stenosis patients. A little number of patients was found during and following winter season was $20(64.52 \%)$ and others season was $11(35.68 \%$ ) show in (Table-1). The patient with infantile hypertrophic pyloric stenosis in this series presented with a number of symptoms. Projectile non bilious vomiting following feeding 30(96.77\%) was the commonest mode of presentation. It was found in all most all cases. Second highest presentation was a mass moving across the upper abdomen was $24(77.42 \%)$ and demanding food following vomiting 29(93.55\%), Failure to thrive 11(35.48\%), Constipation 7(22.58\%) and Jaundice 1(3.22) show in Table-2. Ultra-sonogram of the abdomen was done in all patients clinically diagnosed or suspected as infantile hypertrophic pyloric stenosis. Hypertrophied pylorus was found in 29 patients $(93.55 \%)$ and No hypertrophied pylorus $2(6.45 \%)$. Clinical findings palpable mass $21(67.74 \%)$ and no palpable mass $10(32.26 \%)$ Table- 3 shows ultrasonogram findings of IHPS patients. Correlation of clinical and ultra-sonogram findings with operative finding clinical findings true +ve $20(64.52 \%)$, true - ve $2(6.45 \%)$, false +ve 1(3.23), false -ve 8(25.81) and ultra-sonogram observation true +ve $27(87.10 \%)$, true ve $2(6.45 \%)$, false +ve $2(6.45 \%)$, false -ve $2(6.45 \%)$ and then finally operation needed IHPS ware $29(93.35 \%)$ also others than IHPS $2(6.45 \%)$ show in 
Table-4. Correlation of pattern of sensitivity and specificity in clinical findings $93.1 \%$ and $50 \%$, ultra- sonogram findings $71.43 \%$ and $66.67 \%$ show in Table5.

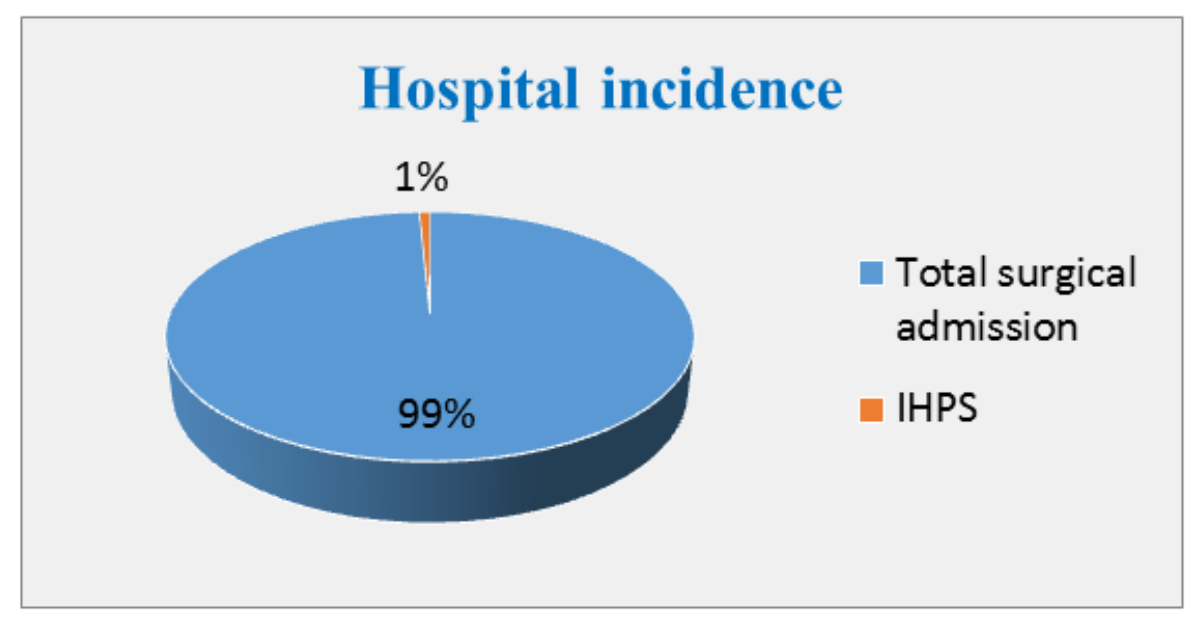

Fig-1: Hospital incidence of the Participants ( $\mathrm{N}=31$ )

Table-1: Socio-economic characteristics of children with IHPS (N=31)

\begin{tabular}{|l|l|l|}
\hline Variables & N & $\%$ \\
\hline Age Distribution(months) & & \\
\hline Age group (Month) & 6 & 19.35 \\
\hline$(0-1)$ & 22 & 70.97 \\
\hline$(1-2)$ & 3 & 9.68 \\
\hline$(2-5)$ & & \\
\hline Socio-economic condition & 9 & 29.03 \\
\hline Socio-economic status & 19 & 61.29 \\
\hline Lower income group & 3 & 9.68 \\
\hline Middle income group & 19 & 61.29 \\
\hline Higher income group & 12 & 38.71 \\
\hline Inhabitant of the patients & 20 & 64.52 \\
\hline Rural & 11 & 35.48 \\
\hline Urban & 27 & 87.10 \\
\hline Seasonal Variation & 4 & 12.90 \\
\hline Winter \\
\hline Other season
\end{tabular}

Table-2: Physical findings of patient with IHPS ( $N=31)$

\begin{tabular}{|l|l|l|}
\hline Feature & $\mathrm{N}$ & $\%$ \\
\hline Projectile vomiting (Non bilious) & 30 & 96.77 \\
\hline Visible peristalsis in Upper abdomen & 24 & 77.42 \\
\hline Demanding food following vomiting & 29 & 93.55 \\
\hline Failure to thrive & 11 & 35.48 \\
\hline Constipation & 7 & 22.58 \\
\hline Jaundice & 1 & 3.23 \\
\hline
\end{tabular}

Table-3: Clinical findings and ultra-sonogram findings of IHPS ( $n=31$ )

\begin{tabular}{|l|l|l|l|l|l|l|l|}
\hline \multicolumn{4}{|c|}{ Clinical Findings } & \multicolumn{4}{l|}{ Ultra sonogram findings } \\
\hline Palpable mass & No palpable mass & \multicolumn{2}{l|}{ Hypertrophied pylorus } & \multicolumn{2}{l|}{ No hypertrophied pylorus } \\
\hline $\mathbf{N}$ & $\mathbf{\%}$ & $\mathbf{N}$ & $\mathbf{\%}$ & $\mathbf{N}$ & $\mathbf{\%}$ & $\mathbf{N}$ & $\mathbf{\%}$ \\
\hline 21 & 67.74 & 10 & 32.26 & 29 & 93.55 & 2 & 6.45 \\
\hline
\end{tabular}


Table-4: Correlation of clinical and ultra-sonogram findings with operative finding $(n=31)$

\begin{tabular}{|c|c|c|c|c|c|c|c|c|c|c|}
\hline \multirow[t]{3}{*}{ Variables } & \multicolumn{4}{|c|}{ Clinical findings } & \multicolumn{4}{|c|}{ Ultra sonogram } & \multicolumn{2}{|c|}{ Operative } \\
\hline & TRUE & FALSE & FALSE & TRUE & TRUE & FALSE & FALSE & TRUE & IHPS & Other \\
\hline & $+\mathrm{ve}$ & $+\mathrm{ve}$ & $-\mathrm{ve}$ & $-v e$ & $+\mathrm{ve}$ & $+\mathrm{ve}$ & $-\mathrm{ve}$ & $-\mathrm{ve}$ & & $\begin{array}{l}\text { than } \\
\text { IHPS }\end{array}$ \\
\hline $\mathrm{N}$ & 20 & 1 & 8 & 2 & 27 & 2 & 2 & 2 & 29 & 2 \\
\hline$\%$ & 64.52 & 3.23 & 25.81 & 6.45 & 87.10 & 6.45 & 6.45 & 6.45 & 93.55 & 6.45 \\
\hline
\end{tabular}

Table-5: Correlation of pattern of sensitivity and specificity in clinical findings and ultra-sonogram findings

\begin{tabular}{|l|l|l|}
\hline Variables & Sensitivity $\mathbf{( \% )}$ & Specificity $(\%)$ \\
\hline Ultra-sonogram examination & 93.1 & 50 \\
\hline clinical findings & 71.43 & 66.67 \\
\hline
\end{tabular}

\section{DISCUSSION}

Among the 31 patients admitted during the study period, 29 patients finally diagnosis as IHPS, and 2 patients were other than IHPS. Out of 29 patients with IPS, 25 patients $(86.2 \%)$ were male and 4 patients $(13.8 \%)$ were female. Male: female ratio was 6.25 . 1 . It is similar with other study. In several studies of large group of children with pyloric stenosis, boys have been affected 5 times more often than girls Young et al., 1994. Our study has also shown the fact of male predominance Male patients with pyloric stenosis (PS) were statistically significant more likely to be first born, in one observation of pyloric stenosis (PS) first born male infant were $71 \%$ [5]. Our study also shown the first born affected male patients with PS $58.06 \%$ which correlated with the above study. Age of the patients ranged from 0 month to 5 months in this study, Peak incidence was observed within 1 - 2 months and lowest incidence observed after 2 months of age. Out of 31 patients within 1-2 months were 22 patients $(70.97 \%)$, within 1 month was 6 patients $(19.35 \%)$ and $3(9.68 \%)$ patients were between $2-5$ month. There were no patients observed beyond 5 month of age. The typical presentation of IHPS usually commence at the age of 34 week $[2,5]$. In one study all patients were aged under 2 months [5]. In another study hypertrophic pyloric stenosis is exceedingly rare in patients over 6 months of age [14] which correlate with the present study. Family history of infantile hypertrophic pyloric stenosis was not informative in this study. No patient had family history of IHPS. Khan and Islam [5] showed that of the 47 patients with pyloric stenosis there was also no family history. In this prospective study, the total number of patients wore 31. The exact aetiology was not found in our study. Many authors also noted that the aetiology of infantile hypertrophic pyloric stenosis remained obscured despite theories involving genetic, environmental and neurologic factors [6]. In Bangladesh most of the people are illiterate and they are not health conscious. Medical facilities are not well equiped. So most of the patients did not get adequate treatment before arrival to specialised hospital. Before arrival to Dhaka Shishu Hospital 5 (16.13\%) patients came to initial contact with specialist doctor, 19 (61 $28 \%$ ) patients with qualified doctor, 1 (3.23\%) patient with homeopathic doctor, $1(3.23 \%)$ patient with pally doctor and $5(16.13 \%)$ patients have got admitted directly. Patient in this series presented with non-bilious projectile vomiting $(97.77 \%)$, visible peristalsis in the upper abdomen passing from left to right $77.42 \%$, hungry following vomiting $93.55 \%$, failure to thrive $35.48 \%$, constipation $22.58 \%$ and jaundice was $3.22 \%$ cases. This study showed that palpable olive shaped mass found in $64.52 \%$ cases, dehydration $96.77 \%$, and anemia was $6.45 \%$ cases, the complication depends upon the duration of symptoms. More the duration of symptoms, more and more will be complications. The usual complication were malnutrition, dehydration and metabolic alkalosis due to electrolyte imbalance, Hypo tonicity and lack of interest in feeding are of serious important complication, suggesting a marked electrolyte upset. A sub normal temperature is also a serious sign [15] which was not found in the present study. The diagnosis of HPS was based on history of non-bilous projectile vomiting, a mass moving across the upper abdomen and palpation of pyloric mass in right hypochondriac region. Ultra-sonogram was helpful in diagnosis of IHPS even in atypical clinical presentation. In present study among 31 patents, ultra-sonogram investigation was done for all patents. Out of 31 patients finally hypertrophic pyloric mass was confirmed by uitrasonography and operatively in 27 patients $(87.1 \%)$. There were 4 diagnostic error 2 patents $(6.45 \%)$ with false positive and 2 patients $(6.45 \%)$ with false negative by ultrasonogram study. Our sensitivity was $93.1 \%$ and specificity was $50 \%$ Godbole [7] shown that of the 75 patients with pyloric stenosis, ultrasound examination was confirmatory in $74(98.6 \%)$ patients. There was one false negative scan in an infant proven to have pyloric stenosis at surgery Ultrasound imaging therefore had a sensitivity of $97 \%$ and specificity of $100 \%$. No false positive scan was noted in the study which does not correlate with the present study. Still now ultrasonogram is not widely used in diagnosis of IHPS, because we needs special paediatric probe. The result may vary with others. Because, the diagnosis of IHPS with ultrasonogram is a highly operator dependant. So skillness is an important factor for diagnosis of IHPS by ultrasonogram. Besides this work load. Relaxed condition of infant during ultrasonography and repeat scan often may not possible 
due to financial problem to diagnose IHPS with ultrasonogram accurately. In the present study all patients examined clinically carefully when the patient was relaxed to identify the pyloric mass. Sometimes it was done on several occasions to evaluate the presence of pyloric mass. Out of 31 patients clinical examination for hypertrophic pyloric mass was positive in $20(64.52 \%)$ patient. There was one false. Positive $(3.22 \%)$ and 8 cases $(25.81 \%)$ were false negative in our study. This large number of false negative result may be due to failure to examine the infant in fully relaxed condition. The pylorus mass may also not detected clinically if it is subhepatic in location. It may also the failure of individual to palpate the bump Our clinical examination had a sensitivity of $71.43 \%$ and specificity $66.67 \%$ Godbole [7] showed that of 75 patients with pyloric stenosis, clinical examination was positive in $60(80 \%)$ patient. There was one false positive examination. Pyloric stenosis could not be detected in 15 patients (20\%). The false negative result was $20 \%$. Clinical examination therefore had a sensitivity of $72 \%$ specificity of $97 \%$ which do not correlate with the present study. Barium meal study of stomach and duodenum was done in $4(12.9 \%)$ patients in our study, 2 patients showed features of gastric outlet obstruction and 2 patients showed normal study and dye easily passed into small intestine. There were absent of associated (GER) gastroesophageal reflux or malrotation in this study. Forman (Forman et al. 1990) showed only $44 \%$ of those with an imaging examination was diagnosed as having HPS and in another series it was $53 \%$ to $75 \%$, which correlate with the present study. In the present study all patients with IHPS had laparotomy for pyloromyotomy operation. During the process of pyloromyotomy one (3.2\%) patient developed duodenal mucosal perforation which was repaired by omental patch and post-operative recovery of this patient was well. Royal [13] reported the rate of mucosal perforation during pyloromyotomy ranging from $0.3 \%$ to $11.5 \%$ which correlated with the present study. Poon [16] shown that there were 7 (23\%) instances of duodenal mucosal perforation out of 303 patients, which is almost similar with the present study. The most common post-operative complications in our study were vomiting in $8(25.81 \%)$ patients, respiratory tract infection in 4 patients $(12.9 \%)$, one patent hod wound infection and one patient - abscess in the limb. Poon [16] showed the rate of wound infection following pyloromyotomy was $3 \%$ to $9 \%$, Khan [5] showed the rate of wound infection following pyloromyotomy was $2.1 \%$ which correlated with the present study. Mortality after pyloromyotomy is at present below $1 \%$ in many countries [5]. In this prospective study there was no mortality. Rasmussen et al., [17] showed that the rate of mortality among surgically treated patients of IHPS was $0.7 \%$. Improvement in pre-operative resuscitation including correction of anaemia, dehydration and electrolyte imbalance and facilities in post-operative management is the reason for reduced mortality, which is now less than $1 \%[17,5]$. All patients in this series were advised to come for follow up but only 4 (12.9\%) patients reported. General condition of all follow up patients were satisfactory. They had good appetite, had satisfactory weight gaining and had no vomiting. There was no recurrence of IHPS or incomplete pyloromyotomy in our series. Parigi [18] reported the recurrence of IHPS in 7 weeks after the first operation. After second pyloromyotomy patient recovered well and there was no complain infollow up Rasmussen [17] showed 2 patients who underwent a second pyloromyotomy operation because of insufficiency of the initial pyloromyotomy. We had no such experience in the present series.

\section{CONCLUSION AND RECOMMENDATIONS}

In conclusion we would like to advice that infantile hypertrophic pyloric stenosis is a most common cause of non-bilious vomiting in an infant. Its diagnosis not so difficult in most cases. The diagnosis being made primarily by palpation of the hypertrophied pylorus. We recommend that ultrasound imaging need not to be carried out as a first line investigation for the diagnosis of pyloric stenosis. The use of ultrasound imaging should be reserved for those cases where clinical examination is doubtful or inconclusive. We would therefore expect early and accurate diagnosis and proper management of infant with IHPS.

Funding: No funding sources.

Conflict of interest: None declared.

Ethical approval: The study was approved by the Institutional Ethics Committee.

\section{REFERENCES}

1. Kobayashi H, O’Briain DS, Puri P. Defective cholinergic innervation in pyloric muscle of patients with hypertrophic pyloric stenosis. Pediatr surg, Int. 1994; 9:338-341.

2. Tam PKH. An immunohistochemical study with neuron specific enolose and substance $\mathrm{P}$ of human enteric innervation- The normal development pattern and abnormal deviations in Hirschsprung's disease and pyloric stenosis. Journal of pediatric surgery. 1986; 21: 227-232.

3. Tam PKH, Saing H, Koo J, Wong J, Ong GB. Pyloric function five to eleven years after Ramstedt's pyloromyotomy, Journal of pediatric surgery. 1985; 20:236-239.

4. Jeffrey SY, Turner CS, Adams RD. Congenital hypertrophic pyloric stenosis. Pediatric surgery Int. 1994; 9:202-203.

5. Khan AR and Islam MK. Diagnosis and management of congenital hypertrophic pyloric stenosis. Dhaka Shishu (Children) Hospital Jouranl. 1993; 9:14-17. 
6. Janik JS, Akbar AM, Burrington JD, Burke G. The role of gastrin in congenital hypertrophic pyloric stenosis. Journal of pediatric surgery. 1978; 13:151-154.

7. Godbole P, Sprigg A, Dickson JAS, Lin PC. Ultrasound compared with clinical examination in infantile hypertrophic pyloric stenosis. Archives of Disease in Childhood: 1996; 335-337.

8. Dudgeon DL. Lesion of the stomach. Ln: Ashcarft KW Holder TM editors, Pediatric surgery. $2^{\text {nd }}$ ed. Philadelphia: WB saunders Company. 1993; 289304.

9. Grant GA, Mc Aleer JJA. Incidence of infantile hypertrophic pyloric stenosis. Lancet 1. 1984; 1177.

10. Benson CF. Infantile hypertrophic pyloric strenosis In: Welch KJ, Randoph JG, Ravitch MM, O’Neill JA, Rowe M, editiors. Pediatric surgery $4^{\text {th }}$ ed vol 2, year book of medical publishers, Inc. 1986; 811-815.

11. Lobe TE. Pyloromyotomy. In: Spitz L, Coran AG editors. Rob \& Smith's operative surgery. Pediatric surgery. 5th ed. Chapman and Hall, 2-6 Boundary Row, Lonkdon SE, 8HN, UK. 1995; 320-327.

12. Hicks LM, Morgan A, Anderson MR. Pyloric stenosis- A report of triplet females and notes on its inheritance. Journal of pediatric surgery. 1981; 16:739-740.

13. Royal RE, Linz DL. Gruppo DL, Ziegler MM. Repair of mucosal perforation during pyloromyotomy. Journal of pediatric surgery. 1995; 30:1430-1432.

14. Abel RM. The ontogeny of the peptide innervation of the human pylorus, with special reference to understanding the aetiology and pathogenesis of infantile hypertrophic pyloric stenosis. Journal of pediatric surgery. 1996 Apr 1;31(4):490-7.

15. Alain JL, Grousseau D, Terrier G. Extramucosal pylorotomy by laparoscopy. Journal of pediatric surgery. 1991 Oct 1;26(10):1191-2.

16. Poon. Alimentary system. In: Willam PL, Bannister LH, Berry MM, editors. Gray's Anatomy. $38^{\text {th }}$ ed. New York chunchill livingstone. 1995; 1683-1812.

17. Rasmussen. Practical epidemiology $84^{\text {th }}$ ed. Churchill Livingstone Edinburg. Scotlan. 1991.

18. Bonnet JP. Is jaundice an early manifestation of Gilbert's syndrome in hypertrophic pyloric stenosis?. Pediatric surgery international. 1995 Jan $1 ; 10(8): 551-2$. 